\title{
A EXPANSÃO DA FRONTEIRA AGRÍCOLA EM GOIÁS
}

\author{
Barsanufo Gomides Borges*
}

\section{Resumo}

O presente estudo analisa o processo de ocupação e colonização em Goiás após 1930, mais especificamente no período da chamada Marcha para o Oeste , iniciada no Estado Novo. O novo padrão de acumulação implantado na economia brasileira, voltado para o mercado interno, exigia a expansão da fronteira agrícola no país. A economia de mercado em expansão e a divisão social do trabalho que se estabeleceu entre indústria e agricultura incrementaram o processo de especialização e modernização na agropecuária regional.

A crise do complexo cafeeiro, no final da década de 1920, não interrompeu o avanço da fronteira agrícola de São Paulo. Pelo contrário, intensificou-a nas décadas seguintes em direção aos estados vizinhos. A atividade agropecuária orientou-se na expansão de lavouras alimentares e na pecuária de corte destinadas ao abastecimento do mercado interno.

A partir desse período ampliou-se a interdependência entre agropecuária e indústria, estabelecendo uma efetiva divisão social do trabalho entre os dois setores da economia. Conseqüentemente, a industrialização do Sudeste do país não pode ser explicada independente de seu setor agropecuário e vice-versa, pois a configuração deste vincula-se, necessariamente, a determinados estágios do desenvolvimento industrial. Uma interdependência similar pode ser constatada no âmbito das atividades comerciais e financeiras vinculadas à produção agropecuária, bem como no âmbito das políticas governamentais voltadas para

* Professor Titular do Departamento de História da Universidade Federal de Goiás. 
o desenvolvimento do setor agrário. ${ }^{1}$ Agropecuária e indústria não constituem, portanto, compartimentos estanques dentro da economia nacional; trata-se de conjuntos de unidades e atividades produtivas que fazem parte de uma mesma divisão social do trabalho.

$\mathrm{Na}$ relação entre o setor agrário e o industrial, os vínculos maiores se estabeleceram, de início, da agropecuária para a indústria, cujos mercados se localizavam predominantemente nas cidades. Foi a partir de 1950 que o setor agrário passou, por sua vez, a constituir um importante mercado para os produtos industrializados; primeiro, apenas para os bens de consumo, e depois, também para os de produção. ${ }^{2} \mathrm{~A}$ demanda de produtos industrializados por parte da massa de produtores rurais somente expandiu-se mais tarde e gradativamente, com a destruição de sua auto-suficiência baseada na policultura alimentar e no artesanato. Através desse processo, o setor industrial não apenas ampliou o mercado para seus produtos, como também fez com que os estabelecimentos agropecuários se especializassem e ampliassem cada vez mais a produção de bens primários. Por sua vez, essa especialização e a crescente produtividade que ela requeria ampliavam as condições de demanda no meio rural, expandindo o mercado de equipamentos e insumos básicos de origem industrial.

A integração do complexo agrário-industrial se deu obedecendo aos imperativos da lei maior da acumulação capitalista e sob o comando do setor industrial. É o progresso da indústria que vem abrindo caminho, comandando a evolução e estabelecendo a lei geral do progresso da agricultura, determinando-lhe, por conseguinte, os limites até onde poderá expandir-se. Isso se traduz na dependência da agro em relação ao grupo de indústrias fornecedoras de insumos básicos e também em relação aos grupos de indústrias transformadoras e compradoras da maior parte dos produtos agrícolas. ${ }^{3}$

Ao estreitarem-se as relações de interdependência entre os dois setores, aprofundou-se a divisão regional do trabalho na economia do país, uma vez que a indústria, ao contrário da agropecuária, está espacialmente concentrada. A subordinação e as relações de trocas de caráter colonial estabelecidas entre o Sudeste industrializado e as regiões agrárias tornaram-se a base da acumulação capitalista na economia brasileira.

$\mathrm{O}$ avanço da fronteira agrícola foi condicionado por fatores 'extra-setoriais' e 'extra-regionais', tais como a implantação e ampliação 
da infra-estrutura de transporte e o crescimento da urbanização e industrialização do país. Os principais agentes financeiros promotores da expansão das 'frentes' de ocupação foram o capital comercial e o bancário, através de empresas colonizadoras vinculadas a companhias de estradas de ferro, grupos econômicos nacionais e estrangeiros e entidades governamentais. ${ }^{4}$

O crescimento e a especialização da agropecuária, entretanto, foram condicionados em seus ritmos pela dimensão e o caráter do novo padrão de acumulação na economia, o qual resultou na concentração do capital no setor industrial localizado no Sudeste e redefiniu a divisão inter-regional do trabalho preexistente no país. Esse processo envolveu, inclusive, a expansão da fronteira agrícola em regiões que aparentemente estavam desvinculadas da economia paulista, como o Rio Grande do Sul, o oeste de Santa Catarina, o sudeste do Paraná e, no Centro-Oeste, o Estado de Goiás, com a implantação de uma infra-estrutura de transportes.

A fronteira agrícola assumiu formas variadas nas diversas regiões do país. Tais variações no tempo e no espaço decorreram não apenas da diversidade da origem dos migrantes que ocuparam as várias áreas de expansão, mas também, e principalmente, das relações de produção que nortearam o processo de povoamento e ocupação econômica dos territórios desbravados.

As migrações internas foram tanto inter-regionais como intraregionais, e não ocorreram apenas no sentido rural-urbano ou vice-versa, mas também na direção rural-rural, ou seja, das áreas rurais estagnadas para as dinâmicas; ou ainda das regiões de fronteira agrícola fechada para as áreas de terras livres ou devolutas. O Estado de Goiás, nesse período, com a fronteira agrícola aberta, recebeu um grande contingente populacional proveniente de outras unidades da federação, expulso com a expansão das relações capitalistas de produção no campo.

A fronteira agrícola paulista, nos moldes e na intensidade que se expandiu a partir de 1930, deve ser vinculada mais ao avanço das relações capitalistas de produção e ao novo padrão de acumulação do que ao eventual dinamismo interno do setor agrário. Isso não quer dizer, porém, que a evolução da agropecuária tenha carecido de maior importância. Pelo contrário, as transformações desse setor foram tão importantes para a industrialização e urbanização como estas para aquelas. ${ }^{5}$

O crescimento e especialização da agropecuária em Goiás, a partir das primeiras décadas do século, foi o resultado lógico do avanço da fronteira agrícola do Sudeste. A implantação de uma infra-estrutura 
de transportes, as mudanças político-institucionais pós-1930, bem como a construção de duas capitais (Goiânia e Brasília) em um intervalo de poucas décadas, serviram de base de sustentação para este avanço da fronteira agrícola no estado. Apesar da aparente autonomia da economia goiana, a especialização da produção agrária estava diretamente vinculada à dinâmica da economia industrial de São Paulo.

Em última análise, a industrialização do Sudeste estimulou a expansão da fronteira agrícola e redefiniu a divisão inter-regional do trabalho, ficando a produção de bens primários, principalmente a de menor valor, a cargo das demais regiões brasileiras. Por um lado, isso incrementou o crescimento e a especialização da economia agrária e, por outro, com a deterioração dos termos de troca em detrimento das áreas agrícolas, os estados agropecuários tiveram que vender cada vez mais produtos primários para comprar os manufaturados que necessitavam.

A economia agrária goiana, como 'criação' do Sudeste, submetera-se a uma forma subordinada de relacionamento econômico que levou a um processo de especialização interna, no sentido de privilegiar a produção de certos bens primários mais exigidos pelo mercado. No intercâmbio comercial, Goiás experimentara nítidas desvantagens diante da baixa produtividade no campo, da pequena agregação de valores à produção, da constante queda no preço dos produtos agropecuários e do alto custo dos transportes. Para o novo padrão de acumulação na economia brasileira, o aviltamento dos preços dos bens primários seria necessário para a redução dos custos de reprodução da força de trabalho no setor urbano-industrial.

A expansão da economia capitalista no Brasil se fez sob forte intervenção e direção do Estado. Após 1930, na ausência de uma burguesia conquistadora ou seja, de uma hegemonia burguesa, o setor público estabeleceu políticas econômicas industrialistas, investiu na criação de uma indústria de base e desempenhou papel decisivo no planejamento do crescimento econômico do país. Este processo de mudanças sócio-econômicas e políticas, imposto de cima para baixo, Luciano Martins denominou de modernização conservadora. ${ }^{6}$

Em Goiás, sociedade agrária tradicional, a ação política do Estado como planejador e executor das mudanças sócio-econômicas e culturais foi de fundamental importância para a modernização da sociedade regional. Após o Movimento de 30, o poder público passou a intervir sistematicamente nas diferentes esferas que compunham a vida social. No âmbito econômico e institucional, criou mecanismos que pro- 
porcionaram o ajustamento da economia goiana ao novo padrão de acumulação que estava sendo implantado no país. Representando o poder central e os interesses das forças oligárquicas dissidentes, o governo revolucionário goiano, na figura do interventor Pedro Ludovico Teixeira, impôs ao estado um projeto de modernização conservadora que veio ao encontro dos interesses do setor agrário local mais progressista (do ponto de vista econômico) e do capital comercial e industrial do Sudeste.

A nova legislação fiscal propunha suprimir gradativamente as taxas sobre as exportações primárias. Apesar das resistências internas no governo, procurou-se cumprir o Decreto 21.418, de 17 de maio de 1932, do Governo Federal, o qual determinava a abolição das barreiras aduaneiras interestaduais e intermunicipais, impondo uma redução anual de $20 \%$ dos impostos de exportação, a partir de 1933, até a sua completa extinção. $\mathrm{O}$ referido decreto, além de incrementar as relações comerciais inter-regionais, vinha ao encontro dos interesses do setor agrário ligado à produção mercantil, uma vez que as taxas que incidiam sobre os produtos primários exportados eram vistas como um entrave ao crescimento e à modernização da agropecuária. ${ }^{7}$

O imposto de exportação era, em Goiás, o principal gerador de receita do erário estadual. Propunha-se substituir essa fonte fiscal pelo imposto territorial rural. ${ }^{8}$ Como boa parte das terras no estado ainda era devoluta, setores do governo resistiram e protelaram tal substituição.

\section{QUADRO 1}

GOIÁS - O IMPOSTO DE EXPORTAÇÃO NO QUADRO GERAL DA ARRECADAÇÃO DO ESTADO (1928-1933)

\begin{tabular}{c|c|c|c}
\hline \multicolumn{3}{|c}{ (Em réis) } \\
\hline ANOS & RECEITA GLOBAL & $\begin{array}{c}\text { RENDA DO IMPOSTO DE } \\
\text { EXPORTAÇÃO }\end{array}$ & $\begin{array}{c}\text { RELAÇÃO PERCENTU- } \\
\text { AL }\end{array}$ \\
\hline 1928 & $5.971: 052 \$ 997$ & $3.163: 453 \$ 230$ & $52,64 \%$ \\
\hline 1929 & $5.450: 754 \$ 802$ & $2.485: 089 \$ 598$ & $27,42 \%$ \\
\hline 1930 & $4.961: 020 \$ 241$ & $2.147: 566 \$ 872$ & $43,28 \%$ \\
\hline 1931 & $6.396: 689 \$ 279$ & $2.986: 794 \$ 568$ & $46,53 \%$ \\
\hline 1932 & $5.962: 157 \$ 640$ & $2.625: 382 \$ 594$ & $44,03 \%$ \\
\hline MÉDIA & $5.748: 334 \$ 986$ & $2.681: 657 \$ 372$ & $46,64 \%$ \\
\hline
\end{tabular}

FONTE: Goiás. Relatório 1930-1933, citado, p. 155. 
Em consonância com a política expansionista do governo Vargas, o interventor Pedro Ludovico Teixeira adotara uma política de ocupação e colonização intensiva em Goiás. A dinâmica dessa ocupação, no entanto, se deu de forma muito heterogênea, variando no tempo e no espaço, conforme os interesses políticos governamentais e as tendências da fronteira econômica e demográfica. Além da política oficial que direcionava o movimento de colonização, outros fatores nortearam o processo de ocupação do espaço no estado: as condições agronômicas da terra, a penetração das vias de transportes e, principalmente, o movimento do capital, ou seja, o avanço da fronteira econômica.

A expansão da fronteira agrícola em Goiás, como em quase todo o país, envolveu simultaneamente ou sucessivamente duas modalidades de ocupação distintas: uma de simples povoamento por posseiros ou ocupantes das novas áreas até então vazias ou escassamente habitadas; outra de apropriação formal dessas áreas por empreendimentos capitalistas, onde a terra e os diversos recursos naturais passaram a ser controlados pelo capital. Neste caso, a maior parte da produção agropecuária se destinava ao mercado e não à subsistência dos próprios produtores.

Em outras palavras, o alargamento da fronteira agrícola no estado de Goiás se deu na forma de 'frente de expansão' e de 'frente pioneira'. Segundo José de Souza Martins, a frente pioneira exprime um movimento social cujo resultado imediato é a incorporação de novas regiões pela economia de mercado. Ela se apresenta como fronteira econômica. Compreendê-la como tal, no entanto, implica considerar que, no caso brasileiro, a fronteira econômica não coincide, necessariamente, com a fronteira demográfica (via de regra aquela está aquém desta). A faixa entre uma e outra, embora sendo povoada (ainda que com baixos índices de densidade demográfica), não constitui uma frente pioneira basicamente porque a sua vida econômica não está estruturada primordialmente a partir de relações com o mercado. ${ }^{9}$ Entretanto, segundo o autor, a frente de expansão, como modalidade de ocupação, não pode ser classificada como economia natural, pois dela saem produtos que assumem valor de troca no mercado.

Com a chegada dos trilhos da estrada de ferro à cidade de Anápolis (1935) e com a implantação da Colônia Agrícola Nacional de Goiás (1941), segundo Waibel, "um novo tipo de povoador veio para Goiás: o pequeno lavrador que cultiva a terra que ele próprio possui e 
vende produtos agrícolas para o mercado. Ele naturalmente se interessou pelas terras com melhor solo, as florestas que os fazendeiros do gado tinham menosprezado". ${ }^{10}$

Conforme dados dos censos demográficos, o estado de Goiás foi uma das unidades da federação que mais recebeu imigrantes e o índice de crescimento populacional, após 1920, foi superior à média nacional. Como a ocupação se fez de forma muito heterogênea, algumas áreas do território goiano permaneceram com a fronteira agrícola aberta até por volta dos anos 60 , coexistindo formas ou modalidades distintas e sobrepostas de ocupação.

Com a implantação de uma infra-estrutura de transportes, o sul e sudeste do estado conheceram, desde as primeiras décadas do século, um processo de ocupação capitalista da terra, enquanto que nas demais regiões esta forma de ocupação do espaço só se efetivou mais tarde. No Mato Grosso de Goiás " e no norte do estado, o povoamento se fez, até por volta dos anos 40 e 50, basicamente por posseiros e colonos de assentamentos, provenientes de diversas áreas do território goiano ou de outras regiões do país, pressionados pela expansão das frentes capitalistas. O colono chegava e ocupava a terra devoluta na esperança de uma futura legalização de sua posse, ou era assentado através do sistema de colônias oficiais ou particulares, onde recebia uma gleba de terra como propriedade para trabalhar com a sua familia.

A ocupação econômica da terra intensificou-se a partir da década de 1950 , com o capital controlando cada vez mais as condições de trabalho, ou seja, a propriedade da terra, expropriando o pequeno proprietário e expulsando o ocupante de sua posse, agravando os conflitos sociais no campo entre fazendeiros-grileiros e posseiros. O capital, que já controlava as relações de troca e apropriava a maior parte da renda da terra, intensifica os investimentos em empreendimentos agropecuários comandando o processo de expansão da fronteira agrícola regional, principalmente no sudoeste, centro e médio-norte do estado. Esta modalidade de ocupação do espaço é denominada de frente pioneira, onde é implantada a propriedade privada da terra $\mathrm{e}$ as relações sociais fundamentais são determinadas pela produção de mercadorias.

A população de Goiás, após 1920, cresceu a taxas superiores às de décadas anteriores, com o Estado aumentando sua participação em relação à população total do país, passando de $1,9 \%$ (1920) para 2,0\% (1940) e chegando a 2,3\% (1950). 
QUADRO 2

GOIÁS/BRASIL - CRESCIMENTO DA POPULAÇÃO

\begin{tabular}{c|c|c|c|c|c}
\hline \multirow{2}{*}{$\begin{array}{c}\text { CEN- } \\
\text { SOS }\end{array}$} & \multirow{2}{*}{ GOIÁS } & ÍNDICE & \multicolumn{2}{|c|}{ PERCENTAGEM } & \multirow{2}{*}{$\begin{array}{c}\text { GOIÁS/ } \\
\text { BRASIL }\end{array}$} \\
\cline { 4 - 5 } & & & BRASIL & ÍNDICE & \\
\hline 1872 & 160.395 & 100 & 9.930 .478 & 100 & $1,6 \%$ \\
\hline 1890 & 227.572 & 142 & 14.333 .915 & 144 & $1,6 \%$ \\
\hline 1900 & $255 / 284$ & 159 & 17.438 .434 & 176 & $1,5 \%$ \\
\hline 1920 & 511 & 919 & 30.635 .605 & 309 & $1,9 \%$ \\
\hline 1940 & 826.414 & 515 & 41.236 .315 & 415 & $2,0 \%$ \\
\hline 1950 & 1.214 .921 & 757 & 51.944 .397 & 523 & $2,3 \%$ \\
\hline
\end{tabular}

FONTE: IBGE - Censo Demográfico de 1950.

O crescimento demográfico em Goiás deveu-se, principalmente, ao intenso movimento migratório a partir dos anos 20. Em 1940, o número de imigrantes no estado atingia 119.466 habitantes, ou seja, $18,9 \%$ da população. De 1940 a 1950 passou a $23,3 \%$ da população total, alcançando 282.452 habitantes, sendo que a taxa de imigração em 1960 subiu para $23,5 \%$, o que, em números absolutos, significava aproximadamente 461.619 pessoas. A taxa de crescimento da população de Goiás, nesse período, foi de $4,9 \%$ ao ano, enquanto que a do país foi de $3,2 \% .^{12}$

Das cinco zonas fisiográficas do estado de Goiás em 1940, a de população mais uniforme e maciçamente rural era a do Norte, onde de 100 habitantes quase 90 residiam no campo. A esta, seguiam-se as zonas sudoeste, sul, a do planalto e centro, com as seguintes percentagens de população rural, respectivamente: $87,03 \% ; 86,55 \% ; 85,78 \%$ e $83,11 \%$. O conjunto do Estado apresentava um índice de ruralidade de $86,51 \%$, um dos mais altos do país.

A população economicamente ativa do estado era, em 1950, de 363.122 habitantes, dos quais $82 \%$ estavam se dedicando às atividades agropecuárias, $6 \%$ à indústria e $12 \%$ ao setor terciário. 
Em 1958, a população goiana chegava a 1.662 .000 habitantes. Entretanto, se comparada com a de outros estados brasileiros esparsamente povoados, a densidade demográfica de Goiás ainda era muito baixa, sendo de apenas 2,67 habitantes por quilômetro quadrado. ${ }^{13}$

QUADRO 3

GOIÁS - SUPERFÍCIE, POPULAÇÃO DE FATO E DENSIDADE POPULACIONAL SEGUNDO AS ZONAS FISIOGRÁFICAS, EM 1940

\begin{tabular}{l|c|c|c|c|c}
\hline \multicolumn{7}{c}{ POPULAÇÃO SOBRE O TOTAL DO ESTADO } \\
\hline $\begin{array}{l}\text { Zona Fi- } \\
\text { siográfica }\end{array}$ & $\begin{array}{c}\text { Superficie } \\
\left(\mathrm{km}^{2)}\right.\end{array}$ & $\begin{array}{c}\text { População } \\
\text { de fato } \\
\text { (Hab.) }\end{array}$ & $\begin{array}{c}\text { Densidade } \\
(\text { Hab./km }\end{array}$ & Superficie & População \\
\hline Norte & 358.839 & 216.538 & 0,60 & 54,28 & $26,18 \%$ \\
\hline Planalto & 68.966 & 146.381 & 2,43 & 10,43 & $17,71 \%$ \\
\hline Centro & 110.968 & 197.644 & 1,78 & 16,78 & $23,92 \%$ \\
\hline Sul-Sudeste & 45.114 & 192.474 & 4,27 & 6,82 & $23,29 \%$ \\
\hline Sudoeste & 77.253 & 73.557 & 0,95 & 11,69 & $8,90 \%$ \\
\hline
\end{tabular}

FONTE: IBGE -Serviço Nacional de Recenseamento -Análise do Censo Demográfico, (354), População de Goiás, 1946, p. 2.

A dinâmica da ocupação e colonização em Goiás, nesse período, se fez calcada na política da conquista do Oeste instituída pelo governo federal. A Marcha para o Oeste, segundo Otávio Guilherme Velho, aparece como um mito. Sobretudo no que diz respeito ao estabelecimento da identidade nacional. ${ }^{14} \mathrm{O}$ Estado autoritário, através do mito da conquista da fronteira, recriou o culto ao espirito bandeirante no processo de ocupação do sertão.

Após a reforma de 10 de Novembro de 1937, incluímos essa cruzada no programa do Estado Novo, dizendo que o verdadeiro sentido de brasilidade é o rumo ao oeste. Para bem esclarecer a idéia, devo 
dizer-vos que o Brasil, politicamente, é uma unidade. Todos falam a mesma lingua, todos têm a mesma tradição histórica e todos seriam capazes de se sacrificar pela defesa do seu território (...). Mas se politicamente o Brasil é uma unidade, não o é economicamente. Sob este aspecto assemelha-se a um arquipélago formado por algumas ilhas, entremeadas de espaços vazios. As ilhas já atingiram um alto grau de desenvolvimento econômico e industrial e as suas fronteiras políticas coincidem com as fronteiras econômicas. Continuam, entretanto, os vastos espaços despovoados, que não atingiram o necessário clima renovador, pela falta de toda uma série de medidas elementares, cuja execução figura no programa do Governo e nos propósitos da administração, destacando-se, dentre elas, o saneamento, a educação e os transportes. No dia em que dispuserem de todos esses elementos, os espaços vazios se povoarăo. Teremos densidade demográfica e desenvolvimento industrial. Deste modo, o programa de 'Rumo ao Oeste' é o reatamento da campanha dos construtores da nacionalidade, dos bandeirantes e dos sertanistas, com a integração dos modernos processos de cultura. Precisamos promover essa arrancada, sob todos os aspectos e com todos os métodos, a fim de suprimirmos os vácuos demográficos do nosso território e fazermos com que as fronteiras econômicas coincidam com as fronteiras políticas. $^{15}$

As palavras de Vargas estão repletas de imagens ideológicas, onde a 'fronteira política' aparece aquém da 'fronteira econômica'. Fazer coincidir essas duas fronteiras significava, para o chefe do Estado Novo, levantar a bandeira ideológica do próprio regime. A ênfase no movimento de fronteira como meios de preencher os espaços vazios entre as 'ilhas econômicas' que formavam o Brasil, aparece portanto como proposta autoritária da criação da 'unidade nacional' e da 'integração', em oposição ao particularismo regional.

O movimento para o oeste vai englobar muitos interesses coincidentes. Os problemas de segurança, de mercado, de fonte de riquezas, de esforço do ideal nacional e de exigência de vasto território acompanham a necessidade de posse da terra para os pequenos lavradores e a possibilidade de dirigir as correntes migratórias, desagravando os problemas e as tensões sociais nos centros urbanos. ${ }^{16}$ Entretanto, não obstante o discurso ideológico de Vargas em defesa da criação do Estado-Nação unificado e progressista, o projeto expansionista além de 
procurar legitimar o governo autoritário, favorecia principalmente a classe dominante. A integração econômica dos espaços regionais se deu em função das necessidades do novo padrão de acumulação voltado para o mercado interno e para o fortalecimento do setor industrial. Ou seja, a ação política do Estado, no sentido de planejar e dirigir a expansão da fronteira econômica e demográfica em nível nacional, atendia mais aos interesses das forças econômicas hegemônicas que controlavam o processo de acumulação do capital.

Em Goiás, a ação do Estado foi de fundamental importância no processo de integração capitalista da economia agrária. O poder público criou condições físicas e institucionais que favoreceram a expansão da fronteira agrícola e a especialização na agropecuária, inserindo-a na divisão inter-regional do trabalho. Entre 1930 e 1945, Goiás conheceu um ativo expansionismo dirigido que ampliou a fronteira econômica e demográfica no estado.

Dentre as ações concretas do poder público no sentido de se incrementar a ocupação econômica e demográfica regional, destacaramse, principalmente, a construção de Goiânia, a nova capital do estado, a implantação da Colônia Agrícola Nacional de Goiás e a criação da Fundação Brasil Central.

A construção de Goiânia ${ }^{17}$ foi um fato marcante dentro do projeto de modernização do estado implementado pelo Interventor Pedro Ludovico Teixeira com apoio do governo central. A transferência da capital para o centro dinâmico da economia regional estabeleceu novas bases de expansão rumo ao oeste. Para o Governo Vargas, tornava-se

imperioso localizar no centro geográfico do país poderosas forças capazes de irradiar e garantir a nossa expansão futura. Do alto dos vossos chapadões infidáveis, onde estarão amanhã, os grandes celeiros do país, deverá descer a onda civilizadora para as planícies do Oeste e do Noroeste. ${ }^{18}$

A construção de Goiânia ideologicamente reforça o mito da conquista da fronteira no Brasil. A nova capital era vista como símbolo de modernização e progresso no oeste brasileiro. Era um referencial urbano em pleno sertão. "Goiânia não representou apenas mais uma cidade a mais no Brasil. Foi o ponto de partida para o primeiro ciclo da expansão do Oeste, fator de desenvolvimento nacional, fator de unifi- 
cação política."19 Goiânia representou, é verdade, um primeiro passo no sentido da ruptura do processo arcaico de organização econômica e política de Goiás.

\section{A Colônia Agrícola Nacional de Goiás}

Implantada na década de 1940 no vale do São Patrício, a Colônia Agrícola Nacional de Goiás foi mais um esforço concreto dos governos federal e estadual no sentido de promover a conquista do oeste através da expansão da fronteira agrícola.

Criada por decreto do ditador Getúlio Vargas, de 14 de fevereiro de 1941, a CANG ficou sob orientação e administração da Divisão de Terras e Colonização do Ministério da Agricultura. Seu fundador e primeiro administrador foi o engenheiro agrônomo Bernardo Sayão.

De acordo com o decreto de fundação, o assentamento teria as seguintes características principais:

a) a área dos lotes deveria variar de 20 a 50 hectares;

b) tais lotes seriam concedidos somente a pessoas reconhecidamente pobres;

c) aos colonos seriam dados, gratuitamente, ferramentas, instrumentos, casas etc.;

d) a terra para o cultivo era também gratuita: os beneficiários não seriam proprietários da gleba, mas somente do que nela produzissem. A expedição definitiva de títulos de propriedade dependeria da outorga do Presidente da República;

e) até a expedição de título definitivo de propriedade, o ocupante de lote não poderia vender, hipotecar, transferir, alugar etc., o lote, a casa e as benfeitorias. Durante o mesmo período ele estaria isento de impostos. ${ }^{20}$

Em 1946, a CANG contava com uma população de aproximadamente oito mil pessoas, das quais cerca de $75 \%$ eram mulatos ou negros. Segundo Waibel,

Na sua grande maioria os habitantes são provenientes de outros estados, predominando entre eles os naturais de Minas Gerais, que formavam cerca de $60 \%$ da população da colônia. Dos restantes, 
$20 \%$ são goianos e $20 \%$ de outros estados, principalmente paulistas e nordestinos, registrando-se, não obstante, famílias até do Rio Grande do Sul. ${ }^{21}$

As famílias vindas de Minas Gerais geralmente chegavam de trem até Anápolis e daí seguiam de caminhão até a colônia. As famílias vindas do norte, oeste e sul do país chegavam geralmente a pé, a cavalo ou de caminhão. "O estado físico e higiênico das famílias que chegam à colônia é geralmente deplorável: maltrapilhos, subnutridos e atacados por males endêmicos, dão-nos a impressão da escória de um povo."22

Até meados da década de 1940, a Secretaria do Conselho de Imigração e Colonização havia aprovado 1.485 lotes de cerca de 30 hectares cada um, ocupando uma área de aproximadamente 44.500 hectares. A área cultivada era de mais ou menos 17.375 hectares, o que correspondia a um terço da área ocupada. ${ }^{23}$

O primeiro administrador da CANG foi Bernardo Sayão, que construiu uma rodovia federal ligando a colônia ao terminal ferroviário de Anápolis.

Para o governo, a Colônia Agrícola Nacional de Goiás tinha como finalidade principal acelerar a conquista e a ocupação do oeste, através da expansão da fronteira agrícola e da modernização da produção no campo. Propunha-se a implantação de pequenas propriedades agrícolas onde seriam utilizados novos métodos de cultura intensiva, substituindo "...velhos hábitos de rotinas nos espíritos dos lavradores". ${ }^{24}$

A criação de colônias agrícolas nacionais no período ditatorial, na verdade, tem relação com a estrutura de poder existente no Brasil pós-1930. Na ausência de uma classe social hegemônica que desse sustentação política ao Governo, Vargas foi forçado a fazer acordos com diversos segmentos da sociedade, inclusive com o setor agrário tradicional, derrotado politicamente em 1930. Conseqüentemente, a própria natureza política e social do estado impedia que o governo atacasse de frente a questão agrária alterando a estrutura fundiária. Nos seus discursos, Vargas demagogicamente falava com freqüência dos males do latifúndio e das vantagens da pequena propriedade da terra para a criação de riquezas. Todavia, ao invés de confrontar diretamente a questão do latifúndio eliminando-o, via na fronteira desocupada o locus para o desenvolvimento da pequena propriedade. Das propostas tenentistas de mudanças na estrutura agrária brasileira, resultaram apenas tímidos projetos de colonização através das colônias agrícolas nacionais. 


\section{QUADRO 5}

\section{PRODUÇÃO DA COLÔNIA AGRÍCOLA NACIONAL DE GOIÁS (1947-1950)}

\begin{tabular}{c|c|c|c}
\hline \multirow{2}{*}{ PRODUTOS } & \multirow{2}{*}{ UNIDADES } & \multicolumn{2}{|c}{ ANOS } \\
\cline { 3 - 4 } & & 1947 & 1950 \\
\hline Arroz & Saca de 60kg & 220.000 & 420.596 \\
\hline Milho & Saca de 60kg & 500.000 & 25.475 \\
\hline Feijão & Saca de 60kg & 65.000 & 18.169 \\
\hline Algodão & Saca de 60kg & 10.000 & 99.213 \\
\hline Farinha & Saca de 60kg & 35.000 & - \\
\hline
\end{tabular}

FONTE: DAYRELL, E. G. Colônia Agrícola Nacional de Goiás. Análise de uma política de colonização na expansão para o Oeste. Op. cit., p. 103.

\section{A Fundação Brasil Central}

Com o objetivo de planejar e coordenar o processo de ocupação e colonização no Centro-Oeste, bem como de garantir a segurança na região, o governo federal, sob a influência da visão geopolítica dos militares, criou a Fundação Brasil Central (Decreto-lei 5.878, de 04 de outubro de 1943). O órgão tinha como finalidade desbravar e dar apoio aos projetos de colonização nas regiões central e ocidental do país, notadamente as áreas cortadas pelos rios Araguaia e Xingu. ${ }^{25}$ Como instrumento da política expansionista do Estado Novo, a Fundação projetou vias de transporte e comunicação terrestres e fluviais, combateu endemias e estudou os recursos naturais da região. $\mathrm{E}$ ainda promoveu pesquisas de apoio à modernização da agropecuária, referentes ao solo, ao clima e às técnicas agrícolas mais apropriadas para as áreas de ocupação. Ou seja, a Fundação Brasil Central foi mais um empreendimento criado pelo poder público para dinamizar a expansão da fronteira rumo ao oeste. 
Em Goiás, no sudoeste e oeste do estado, a Fundação construiu estradas, hospitais e escolas, montou estações radiotelegráficas e armazéns. Com o plano de urbanização do núcleo populacional de Aragarças, procurou fixar a população garimpeira do alto Araguaia. ${ }^{26}$

Em dezembro de 1943, dentro do projeto da Fundação Brasil Central, organizou-se a Expedição Roncador-Xingu com a finalidade de desbravar e reforçar a segurança nacional na fronteira oeste e noroeste do Brasil. Mediante a intervenção do governador Pedro Ludovico Teixeira, a expedição, chefiada pelo tenente-coronel Flaviano de Matos Vanique, teve seu traçado alterado. O ponto de partida dos desbravadores, que seria Aruanã, foi transferido para Aragarças, passando pelo sudoeste goiano e beneficiando a região. ${ }^{27} \mathrm{~A}$ expedição construiu estradas e implantou núcleos de colonização nos estados de Goiás e Mato Grosso.

\section{Mudanças na Política de Ocupação e Colonização}

A queda de Vargas e as novas diretrizes da política econômica do país, após 1945, repercutiram no planejamento e execução dos programas de ocupação do espaço em Goiás. Os principais projetos de colonização implantados entre 1945 e 1950 foram de caráter privado. $\mathrm{O}$ Estado deixou para a iniciativa particular a maioria dos programas de assentamento. Dentre as tentativas de colonização mais importantes, nesse período, destacaram-se a Agro-Colonizadora Industrial Ltda., a Cooperativa Italiana de Técnicos Agricultores (CITAG) e a Colônia dos Deslocados (de guerra) de Itaberaí.

As decisões da I Conferência de Imigração e Colonização, realizada em Goiânia no período de 30 de abril a 7 de maio de 1949, expressaram essa nova política de ocupação do espaço. Promovida pelo Conselho de Imigração e Colonização, órgão da Presidência da República, a Conferência teve como objetivo discutir as novas diretrizes da política de colonização do espaço territorial rural no país, particularmente na região Centro-Oeste. A preocupação central do encontro foi com a ocupação econômica do território e a modernização da agropecuária, e não com a simples fixação do homem à terra.

No final da Conferência concluiu-se que "a finalidade principal da imigração no Brasil, não deve ser a do aumento populacional, mas a 
de sua utilização como elemento de melhoria dos padrões culturais agrícolas ou industriais - existentes no país". ${ }^{28}$ As metas principais da colonização deveriam visar a formação de um tipo de agricultor no qual se resumissem as três funções básicas de uma empresa agrícola-capital, trabalho e administração. Com isso se chegaria à formação de uma sociedade rural radicada ao solo, pela posse da terra, praticando uma agricultura moderna.

Os conferencistas apresentaram às autoridades competentes um conjunto de propostas que orientaria os futuros programas de assentamento no estado. Essas propostas expressavam uma concepção burguesa de ocupação da terra, sugerindo métodos de produção e organização de propriedade típicos de uma sociedade capitalista. A ocupação e colonização da terra deveriam ser implementadas preferencialmente com imigrantes estrangeiros de nível cultural superior ao dos agricultores nativos. Tal modalidade de colonização proposta deveria promover a instalação de núcleos modelares, capazes de agir no sentido de modificar práticas rotineiras já superadas. ${ }^{29}$ Os métodos de cultivo do sertanejo não interessavam às autoridades, preocupadas com a modernização da ocupação do solo. Na visão dos conferencistas, a ocupação da terra em Goiás só teria sentido na medida em que o colono tivesse condição de produzir excedentes agrícolas para o mercado.

Em última análise, o modelo de colonização proposto na Conferência de Goiânia redefiniu a política de ocupação do espaço territorial priorizando os investimentos de capital como forma de incrementar a modernização da produção agrária, adequando-a ao mercado segundo as exigências do novo padrão de acumulação capitalista. Enfim, defendeuse no encontro que o Estado deveria incentivar a expansão da frente pioneira no Centro-Oeste, ou seja, o avanço da fronteira econômica e não apenas da fronteira demográfica.

\section{Notas}

1 Cf. SZMRECSÁNYI, Tamás. "O desenvolvimento da produção agropecuária (1930-1970). In: História geral da civilização Brasileira-O Brasil Republicano. Tomo 3, vol. 4, São Paulo: DIFEL, 1984, p. 113.

3 Cf. BEM-VINDO, Francisco Martins. Acumulação capitalista e urbanização em Goiás (1920-1980). Dissertação de Mestrado 
apresentada ao Departamento de Economia do Instituto de Ciências Humanas da Universidade de Brasília: 1984. p. 68 (mimeo).

4 Cf. SZMRECSÁNYI, Tamás. Op. cit., p. 136.

$5 \quad$ Op. cit., p. 137.

6 MARTINS, Luciano. Pouvoir politique et developpement économique: structure de pouvoir et sisteme de décisions au Brésil. Tese de doutoramento, Paris: 1983 (mimeo).

7 GOIÁS. Relatório apresentado ao governo provisório pelo interventor federal Pedro Ludovico Teixeira, 1930-1933, p. 155.

8 GOIÁS. Relatório de 1930-1933, citado, p. 155.

9 MARTINS, José de Souza. Capitalismo e tradicionalismo. São Paulo: Pioneira, 1975, p. 45.

10 WALBEL, Leo. Capitulos de Geografia tropical e do Brasil. Rio de Janeiro: Fundação Instituto Brasileiro de Geografia e Estatística, 1979 , p. 162.

110 "Mato Grosso de Goiás" compreende a região Centro-Sul do Estado. "Com uma área superior a 20.000 quilômetros quadrados (...) e abrange as matas de Santa Luzia e São Patrício". CABRAL, José Irineu. "O meio físico". In: Goiás - uma nova fronteira humana. Conselho de Migração e Colonização. Rio de Janeiro: 1949, p. 53.

12 Cálculos baseados nos dados dos Censos demográficos (IBGE).

13 GOIÁS. Planos de desenvolvimento econômico de Goiás. Governo Mauro Borges Teixeira, Goiânia: 1961, p. 29.

14 VELHO, Otávio Guilherme. Capitalismo autoritário e campesinato. São Paulo: Difel, 1979, p. 141. Sobre este assunto, conferir também AMADO, Janaína. "Construindo mitos: a conquista do Oeste no Brasil e nos EUA". In: Passando dos limites. Goiânia: Ed. UFG, 1995.

15 VARGAS, s. d., p. 284/85. Apud. VELHO, Octávio Gulherme. Op. cit., p. 148.

16 DAYRELL, Eliane Gracindo. Colônia Agricola Nacional de Goiás: Análise de uma política de colonização na expansão para o Oeste. Dissertação de Mestrado, UFG, Goiânia: 1974, p. 69 (mimeo).

17 Uma análise mais ampla sobre a construção de Goiânia, conferir CHAUL, Nasr F. A construção de Goiânia e a transferência da capital. Dissertação de Mestrado, ICHL/UFG, Goiânia: Ed. UFG, 1988.

18 Instituto Brasileiro de Geografia e Estatística. Conselho Nacional de Geografia. Goiânia. Rio de Janeiro: Serviço Gráfico do IBGE, 1942, p. 125. 
19 FIGUEIREDO, Paulo Augusto. Variação em torno de Goiânia. In: Revista Oeste, jul. 1943, p. 2.

20 Secretaria do Conselho de Imigração de Colonização. Goiás - uma nova fronteira humana. Op. cit., p. 187.

21 WAIBEL, Leo. Op. cit., p. 175.

22 Idem, ibidem.

23 WAIBEL, Leo. Op. cit., p. 182.

24 Secretaria do Conselho de Imigração e Colonização. Goiás - uma nova fronteira humana. Rio de Janeiro: 1949 p. 188. s. n.

25 MEIRELLES, Silo. Brasil Central: notas e impressões. Rio de Janeiro: Biblioteca de Exército, 1960, p. 27.

26 Cf. FRANÇA, Basileu Toledo. Sudoeste - Tentativas de interpretação. Revista do Instituto Histórico e Geográfico de Goiás (7), Goiânia: 1978, p. 56.

27 Entrevista com o sertanista e indigenista Acary de Passos Oliveira, participante da Expedição Roncador-Xingu. O Popular, Goiânia, 8 mai. 1993.

28 FAISSOL, Esperidião. Problema da colonização na Conferência de Goiânia. Revista Brasileira de Geografia. abr./jun. 1949, p. 188.

29 Goiás - uma nova fronteira humana. Op. cit., p. 10-1.

\section{Referências Bibliográficas}

BENVINDO, Francisco Martins. Acumulação capitalista e urbanização em Goiás (1920-1980). Brasília, 1984. Dissertação (Mestrado) Departamento de Economia, Instituto de Ciências Humanas da Universidade de Brasília.

BORGES, Barsanufo Gomides. Goiás: modernização e crise 19201960. São Paulo, 1994. Tese (Doutorado) - Faculdade de Filosofia, Letras e Ciências Humanas, Universidade de São Paulo.

CAMARGO, Aspásia de Alcântara. A Questão agrária: crise de poder e reformas de base. In: FAUSTO, Boris (org.) História geral da civilização brasileira - O Brasil Republicano (10). São Paulo: DIFEL, 1983.

CAMPOS, Francisco Itami. Questão agrária: bases sociais da política goiana (1930-1964). São Paulo, 1985. Tese ( Doutorado) - Faculda- 
de de Filosofia, Letras e Ciências Humanas, Universidade de São Paulo.

CHAUL, Nasr Fayad. A construção de Goiânia e a transferência da Capital. Goiânia: Ed. UFG, 1988.

DAYRELL, Eliane Garcindo. Colônia Agrícola Nacional de Goiás: uma análise de uma política de colonização e expansão para o Oeste. Goiânia, 1974. Dissertação (Mestrado) - Universidade Federal de Goiás.

DOLES, Dalísia E. Martins et al. Interpretação histórica da economia de Goiás e posicionamento do setor agropecuário no contexto econômico e social da região. Goiânia: CEPA, 1978.

FIGUEIREDO, Paulo Augusto. Variação em torno de Goiânia. Revista Oeste, jul. 1943.

MARTINS, José de Souza. Capitalismo e tradicionalismo. São Paulo: Pioneira, 1975.

MARTINS, Luciano. Pouvoir politique et developpement économique: structure de pouvoir et sisteme de décisions au Brésil. Paris, 1983. Tese (Doutorado).

MEIRELLES, Silo. Brasil Central: notas e impressões. Rio de Janeiro: Biblioteca do Exército, 1960.

PIMENTEL, Sidney Valadares et al. Passando dos limites. Goiânia: Editora da UFG, 1995.

RABELO, Francisco C. E. Governo Mauro Borges: tradicionalismo, planejamento e mobilização social em Goiás. Belo Horizonte, 1978. Dissertação (Mestrado) - Departamento de Ciência Política, Universidade Federal de MinasGerais.

SILVA, Ana Lúcia da. A Revolução de 30 em Goiás. São Paulo, 1982. Tese (Doutorado) - Faculdade de Filosofia, Letras e Ciências Humanas, Universidade de São Paulo.

SZMRECSÁNYI, Tamás. O desenvolvimento da produção agropecuária (1930-1970). In: FAUSTO, Boris (org.) História geral da civilização brasileira-Brasil Republicano. São Paulo: DIFEL, Tomo 3, v. $4,1984$.

VILLAS BÔAS, Orlando, VILLAS BÔAS, Cláudio. A marcha para o Oeste. São Paulo: Editora Globo, 1994.

WAIBEL, Leo. Capítulos de Geografia tropical e do Brasil. Rio de Janeiro: IBGE, 1979. 